OPEN ACCESS

Edited by:

Stephen V. Liu,

Georgetown University, United States

Reviewed by:

Chul Kim,

Georgetown University, United States

Sandip Patel,

University of California, San Diego,

United States

${ }^{*}$ Correspondence:

Erin Schenk

erin.schenk@ucdenver.edu

Specialty section:

This article was submitted to

Thoracic Oncology,

a section of the journal

Frontiers in Oncology

Received: 13 February 2019 Accepted: 06 March 2019

Published: 29 March 2019

Citation:

Pacheco JM, Camidge DR Doebele RC and Schenk E (2019) A

Changing of the Guard: Immune

Checkpoint Inhibitors With and

Without Chemotherapy as First Line

Treatment for Metastatic Non-small

Cell Lung Cancer. Front. Oncol. 9:195.

doi: 10.3389/fonc.2019.00195

\section{A Changing of the Guard: Immune Checkpoint Inhibitors With and Without Chemotherapy as First Line Treatment for Metastatic Non-small Cell Lung Cancer}

\author{
Jose M. Pacheco, D. Ross Camidge, Robert C. Doebele and Erin Schenk* \\ Division of Medical Oncology, Department of Internal Medicine, University of Colorado Cancer Center, Aurora, CO, \\ United States
}

Inhibitory antibodies targeting programmed death protein 1 (PD-1) and programmed death ligand 1 (PD-L1) have resulted in improved outcomes for many patients with metastatic non-small cell lung cancer in (NSCLC) in the second-line setting due to their ability to lead to prolonged anti-tumor immune responses. Combining these immunotherapies with platinum-based chemotherapy as first-line treatment has resulted in improved response rates and increased survival when compared to platinumbased chemotherapy alone. Certain patient populations may even benefit from immune checkpoint inhibitors as monotherapy in the first-line setting. The PD-1 inhibitor pembrolizumab is approved as monotherapy or in combination with platinum + pemetrexed for most newly diagnosed patients with metastatic NSCLC, excluding those with a targetable oncogene such as ALK and EGFR. The PD-L1 inhibitor atezolizumab is also approved in combination with bevacizumab + carboplatin + paclitaxel for the same population, with some parts of the world also approving this regimen for patients with ALK rearrangements or EGFR activating mutations. However, there are many other chemo-immunotherapy regimens that have been evaluated as initial treatment in metastatic NSCLC. Additionally, combinations of PD-1 axis inhibitors with cytotoxic T lymphocyte antigen-4 inhibitors have been examined, although none are yet approved. Here we review the clinical data in support of the current first-line approaches across histologies and biomarker subtypes, as well as highlight future research directions revealed by the current data.

Keywords: NSCLC, checkpoint inhibitors, clinical trials, KEYNOTE, CheckMate, IMpower

\section{INTRODUCTION}

Since approval of nivolumab as second line therapy for metastatic squamous non-small cell lung cancer (NSCLC) in 2015, first line treatment options for NSCLC have rapidly evolved to include checkpoint inhibitors (1). Under normal conditions, the immune checkpoints programmed death protein 1 (PD-1), programmed cell death ligand 1 (PD-L1), and cytotoxic T lymphocyte antigen-4 (CTLA-4) are best understood as controls for activated $\mathrm{T}$ cells that limit their subsequent detection and responsiveness to antigen (2). Checkpoint inhibitors that block PD-1 (nivolumab and pembrolizumab) or PD-L1 (atezolizumab, durvalumab, and avelumab) prevent T cell downregulation initiated by PD-1 binding PD-L1 expressed on tumor cells and immune cells 
(3). Ipilimumab and tremelimumab prevent the interaction of CTLA-4 on T cells with CD80 or CD86 on antigen presenting cells, allowing CD28, the co-receptor necessary for effective $\mathrm{T}$ cell stimulation, to bind (4). Currently, a PD-1 axis inhibitor is recommended as first line therapy alone or in combination with chemotherapy for most patients with metastatic NSCLC, excluding those with a targetable oncogene such as $A L K$ and EGFR (1). Here we review the clinical data in support of the current approaches across histologies and biomarker subtypes, as well as highlight the future research directions revealed by the current data.

\section{METHODS}

Trials were identified by searching PubMed without date limits, clinicaltrials.gov and abstracts/presentations from major medical society meetings since 2015 (American Association for Cancer Research annual meeting, American Society of Clinical Oncology annual meeting, European Society of Medical Oncology annual meeting and the International Association on Study of Lung Cancer World Conference on Lung Cancer). Trials not reporting data specific to NSCLC were excluded.

The following search terms were used: KEYNOTE-024, KEYNOTE-042, CheckMate 026, IMpower132, IMpower130, IMpower131, KEYNOTE-407, osimertinib + durvalumab, gefinitib + durvalumab, atezolizumab plus erlotinib, pembrolizumab + gefitinib, pembrolizumab and EGFR, pembrolizumab + erlotinib, nivolumab + crizotinib, alectinib + atezolizumab, KEYNOTE-021, duration PD-1 lung cancer, EGFR pembrolizumab, EGFR nivolumab, EGFR atezolizumab, EGFR durvalumab, EGFR avelumab, $A L K$ pembrolizumab, $A L K$ nivolumab, $A L K$ atezolizumab, $A L K$ durvalumab, and $A L K$ avelumab. This article conforms to the Committee on Publication Ethics (COPE) and the International Committee on Medical Journal Editors (ICMJE) recommendations on ethics.

\section{First Line Immune Checkpoint Inhibitors Without Chemotherapy \\ Pembrolizumab}

Pembrolizumab has been compared to platinum-based doublets as first line systemic therapy in two randomized phase III trials in patients independent of histology and negative for EGFR activating mutations or ALK rearrangements. KEYNOTE-024 enrolled patients with PD-L1 $\geq 50 \%$ and KEYNOTE-042 enrolled patients with $\mathrm{PD}-\mathrm{L} 1 \geq 1 \%$ (5-8).

KEYNOTE-024 led to pembrolizumab becoming an integral part of first line treatment for the approximately $30 \%$ of patients with NSCLC who express PD-L1 $\geq 50 \%$ on tumor cells and lacking EGFR activating mutations or $A L K$ rearrangements (5). This trial demonstrated improvements in objective response rate (ORR), progression free survival (PFS), and overall survival (OS) with pembrolizumab when compared to chemotherapy (Table 1). Notably, improved OS with pembrolizumab monotherapy was observed despite a $62.3 \%$ crossover rate at time of progression on chemotherapy to pembrolizumab. Grade $\geq 3$ treatment related adverse events
(TRAEs) were less with pembrolizumab at $31.2 \%$ vs. $53.3 \%$ with chemotherapy (5-7). This trial resulted in the United States Food and Drug Administration (FDA) approval of pembrolizumab as a first line monotherapy option for patients with any histology NSCLC and PD-L1 $\geq 50 \%(1,9)$.

Similarly, KEYNOTE-042 demonstrated improved OS with pembrolizumab, HR 0.81 (95\%CI, 0.71-0.93) and $p=0.0018$ (Table 1) (8). However, these OS results need to be interpreted with caution as nearly half of patients had PD-L1 $\geq 50 \%$. For patients with PD-L1 of $1-49 \%$ OS was not improved with pembrolizumab monotherapy vs. chemotherapy, HR 0.92 (95\%CI, 0.77-1.11). In agreement with KEYNOTE-024, patients with PD-L1 $\geq 50 \%$ experienced an improved OS with pembrolizumab. In patients with PD-L1 $\geq 1 \%$, the ORR and PFS were similar between the two arms. As reported in KEYNOTE024, pembrolizumab was better tolerated than chemotherapy (8). Pembrolizumab monotherapy is not recommended by the National Comprehensive Cancer Network (NCCN) guidelines or FDA approved for first line treatment in patients with PD-L1 <50\% $(1,9)$.

\section{Nivolumab}

Nivolumab monotherapy does not have a clear role in first line therapy despite its success in the second line setting for immunotherapy-naïve patients. CheckMate-026 was a randomized phase III trial comparing nivolumab to platinumbased doublets as initial systemic therapy in patients with PD-L1 $\geq 5 \%$ (10). Enrolled patients had squamous or nonsquamous NSCLC without activating EGFR mutations or ALK rearrangements. In contrast to the trials with pembrolizumab monotherapy, nivolumab did not demonstrate improvement in any major trial endpoint compared to chemotherapy even when enriching for PD-L1 expression at a level potentially comparable to that in KEYNOTE-024 (Table 1). In patients with PD-L1 $\geq 5 \%$, the PFS HR was 1.15 (95\%CI, 0.91-1.45) and OS HR was 1.02 (95\%CI, 0.80-1.30), and similarly, patients with PD-L1 $\geq 50 \%$ experienced no improvement with nivolumab monotherapy by PFS or OS (1.07 (95\%CI, 0.77-1.49) and 0.90 (95\%CI, 0.63-1.29), respectively) (10). Based on the absence of improved outcomes compared to chemotherapy, nivolumab as monotherapy is neither FDA approved nor listed in the NCCN guidelines for first line treatment of metastatic $\operatorname{NSCLC}(1,9)$.

\section{Nivolumab + Ipilimumab}

Dual checkpoint blockade with nivolumab + ipilimumab was initially tested as first line therapy in CheckMate-012, a single arm phase I trial for patients with any histology NSCLC and any degree PD-L1 staining (13). Nivolumab $3 \mathrm{mg} / \mathrm{kg}$ every 2 weeks and ipilimumab $1 \mathrm{mg} / \mathrm{kg}$ every 6 weeks resulted in an encouraging ORR and 2-year OS, especially in patients with PD$\mathrm{L} 1 \geq 50 \%(13,14)$. Based on these results, a randomized phase III study (CheckMate-227) compared nivolumab + ipilimumab to platinum-based chemotherapy in both PD-L1 positive and PD-L1 negative patients without activating EGFR mutations or $A L K$ rearrangements. In the overall trial population of CheckMate227, nivolumab + ipilimumab modestly improved 1 year PFS compared to platinum-based doublets, HR 0.83 
TABLE 1 | Phase 3 trials of checkpoint inhibitors alone or in combination for first line treatment of metastatic NSCLC.

\begin{tabular}{|c|c|c|c|c|c|c|}
\hline Trial & Histology & $\begin{array}{l}\text { PD-L1 } \\
\text { staining* }\end{array}$ & Therapy & $\begin{array}{l}\text { ORR } \\
(95 \% \mathrm{Cl})\end{array}$ & $\begin{array}{l}\text { Median PFS } \\
(95 \% \mathrm{Cl})\end{array}$ & $\begin{array}{l}\text { Median OS } \\
(95 \% \mathrm{CI})\end{array}$ \\
\hline \multirow[t]{2}{*}{ KEYNOTE-024 $(5,7)$} & $\begin{array}{l}\text { Squamous and } \\
\text { non-squamous }\end{array}$ & $\geq 50 \%$ & Pembrolizumab $(n=154)$ & $45.5 \%(37.4-53.7)$ & $\begin{array}{l}10.3 \mathrm{mo} \\
(6.7-\mathrm{NR})\end{array}$ & $\begin{array}{c}30 \mathrm{mo} \\
(18.3-\mathrm{NR})\end{array}$ \\
\hline & & & Platinum Doublet $(n=151)$ & $29.8 \%$ (22.6-37.8) & $\begin{array}{c}6.0 \mathrm{mo} \\
(4.2-6.2)\end{array}$ & $\begin{array}{c}14.2 \mathrm{mo} \\
(9.8-19.0)\end{array}$ \\
\hline \multirow[t]{3}{*}{ KEYNOTE-042 (8) } & $\begin{array}{l}\text { Squamous and } \\
\text { non-squamous }\end{array}$ & $\geq 50 \%$ & Pembrolizumab $(n=299)$ & $39.5 \%^{\mathrm{a}}$ & $\begin{array}{l}7.1 \mathrm{mo} \\
(5.9-9.0)\end{array}$ & $\begin{array}{c}20 \mathrm{mo} \\
(15.4-24.9)\end{array}$ \\
\hline & & $1-49 \%$ & Pembrolizumab $(n=338)$ & $16.6 \%$ (12.8-21.0) & N/A & $\begin{array}{c}13.4 \\
(10.7-18.2)\end{array}$ \\
\hline & & & Platinum Doublet $(n=337)$ & $21.7 \%(17.4-26.4)$ & N/A & $\begin{array}{c}12.1 \\
(11.0-14.0)\end{array}$ \\
\hline & & & Platinum doublet $(n=212)$ & $33 \%(27.0-40.0)$ & $\begin{array}{c}5.9 \mathrm{mo} \\
(5.4-6.9)\end{array}$ & $\begin{array}{c}13.2 \mathrm{mo} \\
(10.7-17.4)\end{array}$ \\
\hline \multirow[t]{2}{*}{ CheckMate-227 (11) } & $\begin{array}{l}\text { Squamous and } \\
\text { non-squamous }\end{array}$ & Any & $\begin{array}{l}\text { Nivolumab + Ipilimumab } \\
(n=583)\end{array}$ & $\mathrm{N} / \mathrm{A}$ & $\begin{array}{c}4.9 \mathrm{mo} \\
(4.1-5.6)\end{array}$ & $\mathrm{N} / \mathrm{A}$ \\
\hline & & & Platinum doublet $(n=583)$ & N/A & $\begin{array}{l}5.5 \mathrm{mo} \\
(4.6-5.6)\end{array}$ & $\mathrm{N} / \mathrm{A}$ \\
\hline \multirow[t]{3}{*}{ MYSTIC (12) } & $\begin{array}{l}\text { Squamous and } \\
\text { non-squamous }\end{array}$ & $\geq 50 \%$ & Durvalumab $(n=118)$ & $\mathrm{N} / \mathrm{A}$ & N/A & $\begin{array}{c}18.3 \mathrm{mo} \\
(13.6-22.8)\end{array}$ \\
\hline & & & $\begin{array}{l}\text { Durvalumab + Tremelimumab } \\
(n=108)\end{array}$ & N/A & N/A & $\begin{array}{c}15.2 \mathrm{mo} \\
(8.0-26.5)\end{array}$ \\
\hline & & & Platinum doublet $(n=107)$ & N/A & N/A & $\begin{array}{c}12.7 \mathrm{mo} \\
(10.3-15.1)\end{array}$ \\
\hline
\end{tabular}

${ }^{*}$ PD-L1 staining on tumor cells was defined by the 22C3 assay for pembrolizumab, the Dako 28-8 assay for nivolumab and the SP263 assay for durvalumab. Platinum includes either carboplatin or cisplatin.

${ }^{a}$ Confidence interval not available.

PD-L1, programmed death ligand 1; ORR, objective response rate; PFS, progression free survival; OS, overall survival; Cl, confidence interval; mo, months; NR, not reached; NE, not evaluable; N/A, not available.

(95\%CI, 0.72-0.96) but did not improve median PFS or OS (Table 1). The incidence of grade 3-4 TRAEs were similar with nivolumab + ipilimumab at $31.2 \%$ when compared to platinumbased doublets at $36.1 \%$. Nivolumab + ipilimumab is not in the NCCN guidelines or FDA approved for use in NSCLC $(1,9)$.

\section{Durvalumab + Tremelimumab}

The MYSTIC trial evaluated first line durvalumab \pm tremelimumab compared to platinum-based doublets (12). Patients of any histology NSCLC with any PD-L1 expression who lacked EGFR activating mutations or $A L K$ rearrangements were enrolled. None of the prespecified primary endpoints for patients with PD-L1 expression $\geq 25 \%$ were met (Table 1). In those patients, durvalumab and tremelimumab did not improve PFS or OS compared to chemotherapy, HR 1.05 (95\%CI, 0.72-1.53) and
HR 0.85 (95\%CI, 0.61-1.17), respectively. Similarly, durvalumab monotherapy did not improve OS compared to chemotherapy in patients with PD-L1 $\geq 25 \%$ [HR 0.76 (95\%CI, 0.56-1.02)] (12). Even in exploratory analysis, patients with PD-L1 $\geq 50 \%$ experienced no significant improvements in OS with either immunotherapy regimen (Table 1). No new safety signals emerged in the immunotherapy arms and TRAEs were less compared to platinum-based doublets (12). This combination is not part of NCCN guidelines or FDA approved for patients with $\operatorname{NSCLC}(1,9)$.

\section{Avelumab}

A phase Ib single arm study evaluated avelumab in patients regardless of PD-L1 staining levels who lacked EGFR activating mutations or $A L K$ rearrangements (15). The ORR was $18.7 \%$ and 
the median PFS was 2.71 months (95\% CI, 1.56-4.18). A phase III trial is forthcoming randomizing patients of any histology NSCLC to avelumab alone or histology directed platinum doublets (NCT02576574).

\section{First Line Immune Checkpoint Inhibition With Chemotherapy \\ Non-squamous Histology \\ Pembrolizumab + platinum (carboplatin or cisplatin) + pemetrexed}

Due to low or absent PD-L1 tumor expression, the majority of patients with metastatic non-squamous NSCLC are not eligible for pembrolizumab monotherapy. Patients with PD-L1 $<50 \%$ and those with PD-L1 $\geq 50 \%$ were enrolled in KEYNOTE189 , which compared the combination of pembrolizumab + platinum + pemetrexed to platinum + pemetrexed. Patients with activating EGFR mutations or $A L K$ rearrangements were excluded. Platinum and pemetrexed were administered together for 4 cycles, followed by maintenance pemetrexed. Pembrolizumab was given every 3 weeks for up to 35 cycles $(16,17)$.

All efficacy endpoints were improved with the addition of pembrolizumab to chemotherapy across PD-L1 subgroups: PDL1 negative, PD-L1 $1-49 \%$ and PD-L1 $\geq 50 \%$, except for PFS in PD-L1 negative patients (Table 2) $(16,17)$. For the entire cohort, the ORR was $47.6 \%$ with pembrolizumab + chemotherapy and $18.9 \%$ with chemotherapy (HR not provided, $p<0.001$ ). Triplet therapy improved PFS and OS vs. chemotherapy, (HR 0.52, $p<0.001$ and HR 0.49, $p<0.01$, respectively). Notably, for the PD-L1 $\geq 50 \%$ subgroup, the benefits of pembrolizumab + chemotherapy were more pronounced. The ORR was $61.4 \%$ with pembrolizumab + chemotherapy $(n=132)$ vs. $22.9 \%$ $(n=70)$ with chemotherapy $(p<0.0001)$. The PFS and OS were also prolonged with pembrolizumab + chemotherapy (HR 0.36 (95\% CI $0.25-0.52$ ) and HR 0.42 (95\% CI $0.24-0.68$ ), respectively) (Table 2) $(16,17)$. Pembrolizumab plus platinum and pemetrexed for first line management of non-squamous NSCLC is listed in the NCCN guidelines and FDA approved regardless of the PD-L1 staining level $(1,9)$.

The addition of pembrolizumab in this trial resulted in a minimal increase in the overall adverse event rate when compared to chemotherapy (grade $\geq 3$ in $67.2 \%$ vs. $65.8 \%$ ) and this did not appear to differ significantly by the type of platinum used. As expected, the immune mediated adverse event rate was higher with the addition of pembrolizumab (all grades $22.7 \%$ vs. $11.9 \%$, grade $\geq 3$ in $8.9 \%$ vs. $4.5 \%$ ). With regards to any etiology adverse event, diarrhea, and rash were significantly more common with the addition of pembrolizumab (diarrhea: all grades $30.9 \%$ vs. $21.3 \%$ and grade $\geq 3$ in $5.2 \%$ vs. $3.0 \%$; rash: all grades $20.2 \%$ vs. $11.4 \%$, grade $\geq 3$ in $1.7 \%$ vs. $1.5 \%$ ). Additionally, incidence of neutropenic fever was greater with pembrolizumab; however, overall incidence of this was low $(16,17)$.

\footnotetext{
Atezolizumab + bevacizumab + carboplatin + paclitaxel Atezolizumab is the only other checkpoint inhibitor with a first line approval in metastatic NSCLC based on IMpower150 which compared atezolizumab + bevacizumab + carboplatin + paclitaxel $(\mathrm{ABCP})$ to bevacizumab + carboplatin + paclitaxel
}

(BCP) in patients with any level PD-L1. Chemotherapy + bevacizumab was administered for 4-6 cycles. Bevacizumab \pm atezolizumab was administered every 3 weeks until disease progression or death (18).

In contrast to most other studies, patients with activating EGFR mutations or $A L K$ rearrangements were allowed to enroll if they had progressed on or were unable to tolerate at least one tyrosine kinase inhibitor (TKI) but excluded from the primary end point assessment. All efficacy endpoints were improved with ABCP vs. BCP (Table 2) (18-20). Across all PD-L1 subgroups, $\mathrm{ABCP}$ significantly improved PFS compared to BCP. As noted in other immunotherapy trials, patients with tumor PD-L1 expression $\geq 50 \%$ or, unique to atezolizumab PD-L1 assessment, immune cell PD-L1 expression $\geq 10 \%$, had a greater magnitude of benefit with the addition of atezolizumab (Table 2) (18-20). ABCP is listed in the NCCN guidelines for first line therapy in patients with advanced non-squamous NSCLC, as well as for patients with EGFR activating mutations or ALK rearrangements who have progressed on at least one prior TKI. While FDA approved for front line therapy in patients with advanced nonsquamous NSCLC, the FDA approval does not include patients with $E G F R$ activating mutations or $A L K$ rearrangements $(1,9)$.

The addition of atezolizumab in this trial resulted in no difference in the incidence of any grade TRAEs, but an increase in grade 3-4 TRAEs was seen (55.7\% vs. $45.7 \%)$. Immune mediated adverse events occurred with a greater frequency with the addition of atezolizumab. Similar to what was seen in KEYNOTE-189, the addition of atezolizumab lead to a higher incidence of rash and febrile neutropenia (rash: grade 1-2 in $12.0 \%$ vs. $5.1 \%$ and grade $3-4$ in $1.3 \%$ vs. $0 \%$; febrile neutropenia: grade $1-2$ in $0.5 \%$ vs. $0 \%$, grade $3-4$ in $8.4 \%$ vs. $5.8 \%$, and grade 5 in $0.8 \%$ vs. $0 \%)(18-20)$.

\section{Atezolizumab + carboplatin + nab-paclitaxel}

IMpower130, a key corollary to IMpower150, compared atezolizumab + carboplatin + nab-paclitaxel to carboplatin + nab-paclitaxel in patients regardless of PD-L1 staining, including patients with activating $E G F R$ mutations or $A L K$ rearrangements after 1st line TKI. Carboplatin + nab-paclitaxel was administered for 4-6 cycles. Patients receiving chemotherapy alone were treated with either placebo or pemetrexed every 3 weeks. Atezolizumab was administered every 3 weeks until disease progression or death (21).

As in IMpower150, enrolled EGFR, or $A L K+$ patients were not included in the primary analysis. Adding atezolizumab to chemotherapy improved PFS and OS in the entire trial population (Table 2) (21). Subgroup analyses based on PDL1 levels observed a PFS improvement regardless of PD-L1 expression, but none experienced a significant OS benefit with the addition of atezolizumab. Grade $\geq 3$ TRAEs were $74.9 \%$ with atezolizumab + chemotherapy vs. $60.7 \%$ with chemotherapy (21). This regimen is neither FDA approved nor in the NCCN guidelines for non-squamous NSCLC $(1,9)$.

\section{Atezolizumab + platinum (carboplatin or cisplatin) + pemetrexed \\ IMpower132, an ongoing phase III trial, is testing the chemotherapy backbone from KEYNOTE-189 with}


TABLE 2 | Phase 3 trials of checkpoint inhibitors plus chemotherapy for first line treatment of metastatic non-squamous NSCLC.

\begin{tabular}{|c|c|c|c|c|c|c|}
\hline Trial & PD-L1 staining* & Therapy & ORR (95\% Cl) & Median PFS (95\% Cl) & $\begin{array}{l}\text { Median OS } \\
(95 \% \mathrm{Cl})\end{array}$ & $\begin{array}{l}1 \text { year OS } \\
(95 \% \mathrm{Cl})\end{array}$ \\
\hline \multirow[t]{4}{*}{$\begin{array}{l}\text { KEYNOTE-189 } \\
(16,17)\end{array}$} & $\mathrm{TC} \geq 50 \%$ & $\begin{array}{l}\text { Pembrolizumab + Platinum + } \\
\text { Pemetrexed }(n=132)\end{array}$ & $61.4 \%(52.5-69.7)$ & $9.4 \mathrm{mo}(9.0-13.8)$ & NR & $73 \%{ }^{a}$ \\
\hline & & Platinum + Pemetrexed $(n=70)$ & $22.9 \%(13.7-34.4)$ & $4.7 \mathrm{mo}(3.1-6.0)$ & $\begin{array}{l}10.0 \mathrm{mo} \\
(7.5-\mathrm{NE})\end{array}$ & $48.1 \%{ }^{a}$ \\
\hline & Any & $\begin{array}{l}\text { Pembrolizumab + Platinum + } \\
\text { Pemetrexed }(n=410)\end{array}$ & $47.6 \%(42.6-52.5)$ & $8.8 \mathrm{mo}(7.6-9.2)$ & NR & $\begin{array}{c}69.2 \% \\
(64.1-73.8)\end{array}$ \\
\hline & & $\begin{array}{l}\text { Platinum }+ \text { Pemetrexed } \\
(n=206)\end{array}$ & $18.9 \%(13.8-25.0)$ & $4.9 \mathrm{mo}(4.7-5.5)$ & $\begin{array}{l}11.3 \mathrm{mo} \\
(8.7-15.1)\end{array}$ & $\begin{array}{c}49.4 \% \\
(42.1-56.2)\end{array}$ \\
\hline \multirow[t]{4}{*}{$\begin{array}{l}\text { IMpower150 } \\
(18-20)\end{array}$} & $\begin{array}{l}T C \geq 50 \% \text { or } I C \geq \\
10 \%^{b}\end{array}$ & $\begin{array}{l}\text { Atezolizumab + Bevacizumab + } \\
\text { Carboplatin + Paclitaxel }(n=71)\end{array}$ & $69 \%^{a}$ & 12.6 mo (10.9-23.4) & $25.2^{\mathrm{a}}$ & $\mathrm{N} / \mathrm{A}$ \\
\hline & & $\begin{array}{l}\text { Bevacizumab + Carboplatin + } \\
\text { Paclitaxel }(n=64)\end{array}$ & $49 \%{ }^{a}$ & $6.8 \mathrm{mo}(5.6-8.4)$ & $15.0^{\mathrm{a}}$ & $\mathrm{N} / \mathrm{A}$ \\
\hline & Any & $\begin{array}{l}\text { Atezolizumab + Bevacizumab + } \\
\text { Carboplatin + Paclitaxel } \\
(n=356)\end{array}$ & $63.5 \%(58.2-68.5)$ & $8.3 \mathrm{mo}(7.7-9.8)$ & $\begin{array}{c}19.2 \mathrm{mo} \\
(18.0-23.8)\end{array}$ & $\begin{array}{c}67.3 \% \\
(62.4-72.2)\end{array}$ \\
\hline & & $\begin{array}{l}\text { Bevacizumab + Carboplatin + } \\
\text { Paclitaxel }(n=336)\end{array}$ & $48 \%(42.5-53.6)$ & $6.8 \mathrm{mo}(6.0-7.1)$ & $\begin{array}{c}14.7 \mathrm{mo} \\
(13.3-16.9)\end{array}$ & $\begin{array}{c}60.6 \% \\
(55.3-65.9)\end{array}$ \\
\hline \multirow[t]{4}{*}{ IMpower130 (21) } & $\begin{array}{l}T C \geq 50 \% \text { or } I C \geq \\
10 \%^{b}\end{array}$ & $\begin{array}{l}\text { Atezolizumab + Carboplatin }+ \\
\text { Nab-paclitaxel }(n=88)\end{array}$ & $\mathrm{N} / \mathrm{A}$ & 6.4 mo (5.49-9.76) & $\begin{array}{c}17.3 \mathrm{mo} \\
(14.78-\mathrm{NR})\end{array}$ & $\mathrm{N} / \mathrm{A}$ \\
\hline & & $\begin{array}{l}\text { Carboplatin + Nab-paclitaxel } \\
(n=42)\end{array}$ & $\mathrm{N} / \mathrm{A}$ & $4.6 \mathrm{mo}(3.22-7)$ & $\begin{array}{c}16.0 \mathrm{mo} \\
(10.94-\mathrm{NR})\end{array}$ & $\mathrm{N} / \mathrm{A}$ \\
\hline & Any & $\begin{array}{l}\text { Atezolizumab + Carboplatin + } \\
\text { Nab-paclitaxel }(n=451)\end{array}$ & $49.2 \%{ }^{a}$ & 7.0 mo (6.2-7.3) & $\begin{array}{c}18.6 \mathrm{mo} \\
(16-21.2)\end{array}$ & $63.1 \%{ }^{a}$ \\
\hline & & $\begin{array}{l}\text { Carboplatin + Nab-paclitaxel } \\
(n=228)\end{array}$ & $31.9 \%{ }^{a}$ & $5.5 \mathrm{mo}(4.4-5.9)$ & $\begin{array}{c}13.9 \mathrm{mo} \\
(12.0-18.7)\end{array}$ & $55.5 \%{ }^{a}$ \\
\hline \multirow[t]{4}{*}{ IMpower132 (22) } & $\begin{array}{l}T C \geq 50 \% \text { or } I C \geq \\
10 \%^{b}\end{array}$ & $\begin{array}{l}\text { Atezolizumab + Platinum + } \\
\text { Pemetrexed }(n=25)\end{array}$ & $72 \%{ }^{a}$ & $10.8 \mathrm{mo}^{\mathrm{a}}$ & $\mathrm{N} / \mathrm{A}$ & $\mathrm{N} / \mathrm{A}$ \\
\hline & & Platinum + Pemetrexed $(n=20)$ & $55 \%{ }^{a}$ & $6.5 \mathrm{mo}^{\mathrm{a}}$ & N/A & N/A \\
\hline & Any & $\begin{array}{l}\text { Atezolizumab + Platinum + } \\
\text { Pemetrexed }(n=292)\end{array}$ & $47 \%^{\mathrm{a}}$ & $7.6 \mathrm{mo}(6.6-8.5)$ & $\begin{array}{c}18.1 \mathrm{mo} \\
(13.0-\mathrm{NE})\end{array}$ & $\mathrm{N} / \mathrm{A}$ \\
\hline & & $\begin{array}{l}\text { Platinum + Pemetrexed } \\
(n=286)\end{array}$ & $32 \%{ }^{a}$ & $5.2 \mathrm{mo}(4.3-5.6)$ & $\begin{array}{c}13.6 \mathrm{mo} \\
(11.4-15.5)\end{array}$ & $\mathrm{N} / \mathrm{A}$ \\
\hline
\end{tabular}

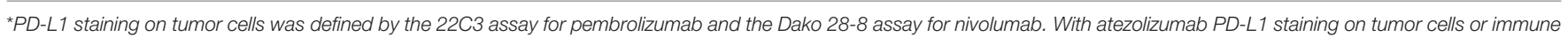
cells was done using the SP142 assay. Platinum includes either carboplatin or cisplatin.

${ }^{a}$ Confidence interval not available.

${ }^{b}$ For the IMpower studies patients with $P D-L 1 \geq 50 \%$ on tumor cells or $P D-L 1 \geq 10 \%$ immune cells are grouped together as $P D-L 1$ high staining.

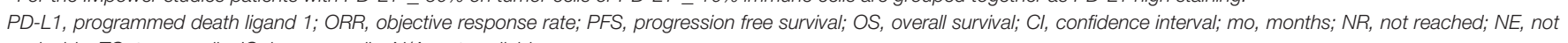
evaluable; TC, tumor cells; IC, immune cells; N/A, not available.

atezolizumab in patients with any level PD-L1 excluding those with activating EGFR mutations or $A L K$ rearrangements. Platinum + pemetrexed was given for 4-6 cycles, followed by pemetrexed maintenance. Atezolizumab was administered every 3 weeks until disease progression or death (22).

Similar to KEYNOTE-189, the ORR and PFS were improved when the checkpoint inhibitor atezolizumab was added to chemotherapy (Table 2). However, at the interim analysis, the OS for the entire cohort was not prolonged with the addition of atezolizumab to chemotherapy, HR 0.81 (95\%CI, 0.64-1.03) (22). In early subgroup analysis, patients with tumor PD-L1 $\geq 50 \%$ or immune cell $\mathrm{PD}-\mathrm{L} 1 \geq 10 \%$ appear to have a greater magnitude of benefit with the addition of atezolizumab (Table 2) (22). This regimen is neither FDA approved nor in the NCCN guidelines for non-squamous NSCLC $(1,9)$.

\section{Squamous Histology}

\section{Pembrolizumab + carboplatin + taxane (nab-paclitaxel or} paclitaxel)

Extrapolating from the success of adding pembrolizumab to frontline chemotherapy in non-squamous histology, KEYNOTE407 compared carboplatin + a taxane with $(n=278)$ or without pembrolizumab $(n=281)$ in patients with squamous histology and any level PD-L1. Carboplatin + taxane was administered for 4 cycles. Pembrolizumab was given every 3 weeks for up to 35 cycles $(23,24)$.

All efficacy endpoints were improved with the addition of pembrolizumab to chemotherapy across PD-L1 subgroups: PD-L1 negative, PD-L1 1-49\%, and PD-L1 $\geq 50 \%$, except for OS in patients with $\mathrm{PD}-\mathrm{L} 1 \geq 50 \%$ (Table 3 ). While there was not a statistically significant increase in OS for patients with $\mathrm{PD}-\mathrm{L} 1 \geq 50 \%$ administered pembrolizumab + chemotherapy 
TABLE 3 | Phase 3 trials of checkpoint inhibitors plus chemotherapy for first line treatment of metastatic squamous NSCLC.

\begin{tabular}{|c|c|c|c|c|c|c|}
\hline Trial & PD-L1 staining* & Therapy & ORR (95\% Cl) & Median PFS (95\% Cl) & $\begin{array}{l}\text { Median OS } \\
\text { (95\% Cl) }\end{array}$ & $\begin{array}{l}1 \text { year OS } \\
(95 \% \mathrm{Cl})\end{array}$ \\
\hline \multirow[t]{4}{*}{$\begin{array}{l}\text { KEYNOTE-407 } \\
(23,24)\end{array}$} & $\mathrm{TC} \geq 50 \%$ & $\begin{array}{l}\text { Pembrolizumab + Carboplatin + } \\
\text { Paclitaxel or Nab-Paclitaxel } \\
(n=103)\end{array}$ & $60.3 \%(48.1-71.5)$ & $8.0 \mathrm{mo}(6.1-10.3)$ & NR (11.3-NE) & $63.4 \%^{\mathrm{a}}$ \\
\hline & & $\begin{array}{l}\text { Carboplatin + Paclitaxel or } \\
\text { Nab-Paclitaxel }(n=104)\end{array}$ & $32.9 \%(22.3-44.9)$ & $4.2 \mathrm{mo}(2.8-4.6)$ & $\mathrm{NR}$ (7.4-NE) & $51.0 \%{ }^{a}$ \\
\hline & Any & $\begin{array}{l}\text { Pembrolizumab + Carboplatin + } \\
\text { Paclitaxel or Nab-Paclitaxel } \\
(n=278)\end{array}$ & $57.9 \%(51.9-63.8)$ & 6.4 mo (6.2-8.3) & $\begin{array}{c}15.9 \mathrm{mo} \\
(13.2-\mathrm{NR})\end{array}$ & $65.2 \%^{a}$ \\
\hline & & $\begin{array}{l}\text { Carboplatin + Paclitaxel or } \\
\text { Nab-Paclitaxel }(n=281)\end{array}$ & $38.4 \%(32.7-44.4)$ & $4.8 \mathrm{mo}(4.3-5.7)$ & $\begin{array}{c}11.3 \mathrm{mo} \\
(9.5-14.8)\end{array}$ & $48.3 \%^{\mathrm{a}}$ \\
\hline \multirow[t]{4}{*}{ IMpower131 (25) } & $\begin{array}{l}T C \geq 50 \% \text { or } I C \geq \\
10 \%^{b}\end{array}$ & $\begin{array}{l}\text { Atezolizumab + Carboplatin + } \\
\text { Nab-paclitaxel }(n=53)\end{array}$ & $60 \%^{a}$ & $10.1 \mathrm{mo}^{\mathrm{a}}$ & $23.6 \mathrm{mo}^{\mathrm{a}}$ & $\mathrm{N} / \mathrm{A}$ \\
\hline & & $\begin{array}{l}\text { Carboplatin + Nab-paclitaxel } \\
(n=48)\end{array}$ & $33 \%{ }^{a}$ & $5.5 \mathrm{mo}^{\mathrm{a}}$ & $14.1 \mathrm{mo}^{\mathrm{a}}$ & N/A \\
\hline & Any & $\begin{array}{l}\text { Atezolizumab + Carboplatin }+ \\
\text { Nab-paclitaxel }(n=343)\end{array}$ & $49 \%^{a}$ & 6.3 mo (5.7-7.1) & $\begin{array}{c}14.0 \mathrm{mo} \\
(12.0-17.0)\end{array}$ & $\mathrm{N} / \mathrm{A}$ \\
\hline & & $\begin{array}{l}\text { Carboplatin + Nab-paclitaxel } \\
(n=340)\end{array}$ & $41 \%^{a}$ & 5.6 mo (5.5-5.7) & $\begin{array}{c}13.9 \mathrm{mo} \\
(12.3-16.4)\end{array}$ & $\mathrm{N} / \mathrm{A}$ \\
\hline
\end{tabular}

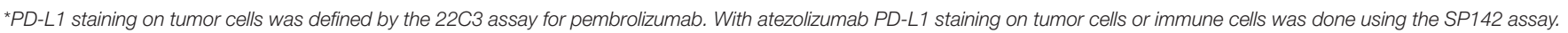
Platinum includes either carboplatin or cisplatin.

${ }^{a}$ Confidence interval not available.

${ }^{b}$ For the IMpower131 study patients with $P D-L 1 \geq 50 \%$ on tumor cells or PD- L1 $\geq 10 \%$ immune cells are grouped together as $P D-L 1$ high

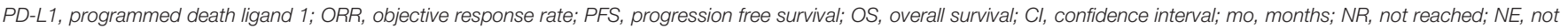
evaluable; TC, tumor cells; IC, immune cells; N/A, not available.

(HR $0.64,95 \%$ CI $0.37-1.10$ ), this could reflect the relatively short follow-up and may become statistically significant in the future $(23,24)$. This combination is in the NCCN guidelines and FDA approved for first line management of squamous histology NSCLC regardless of PD-L1 staining level $(1,9)$.

The addition of pembrolizumab led to no significant increase in the overall adverse event rate, grade $\geq 3$ in $69.8 \%$ vs. $68.2 \%$. Immune mediated adverse events and infusion reactions were more common in patients receiving pembrolizumab (all grades $28.8 \%$ vs. $8.6 \%$, grade $\geq 3$ in $10.3 \%$ vs. $3.2 \%$ ). Alopecia (all grades $46.0 \%$ vs. $36.4 \%$ ) and puritis were higher with the addition of pembrolizumab; however, there was no significant increase in the incidence of diarrhea, rash or febrile neutropenia $(23,24)$.

\section{Atezolizumab + carboplatin + nab-paclitaxel}

IMpower131, an ongoing phase III trial, is comparing carboplatin + nab-paclitaxel with $(n=343)$ or without atezolizumab ( $n=340)$ regardless of PD-L1 status. Chemotherapy was administered for 4 or 6 cycles. Atezolizumab was given every 3 weeks until disease progression or death (25).

At the prespecified interim analysis, the addition of atezolizumab to chemotherapy improved ORR. While atezolizumab + chemotherapy prolonged PFS, it did not improve OS (HR 0.96, 95\%CI 0.78-1.18) (Table 3) (26). As reported in the other IMpower trials, patients with high PD-L1 (tumor cells $\geq 50 \%$ or immune cells $\geq 10 \%$ ) experienced a greater magnitude of benefit with addition of atezolizumab to chemotherapy (Table 3). Grade $\geq 3$ TRAEs were $69 \%$ with atezolizumab + chemotherapy vs. $58 \%$ with chemotherapy (25). This regimen is neither FDA approved nor in the NCCN guidelines for squamous histology $\operatorname{NSCLC}(1,9)$.

\section{Immune Checkpoint Inhibitors for Oncogene Addicted NSCLC}

\section{First Line Checkpoint Inhibitor Monotherapy}

As checkpoint inhibitors emerged as a viable therapeutic option for NSCLC and other malignancies, multiple approaches attempted to incorporate checkpoint inhibitors alone or in combination for the management of NSCLC with an oncogenic driver. Ideally, the non-overlapping mechanisms of action of checkpoint inhibitors and TKIs would result in a deeper or longer duration of response. Early enthusiasm was high as it was common for lung cancers with activating EGFR mutations or $A L K$ rearrangement to also express $\mathrm{PD}-\mathrm{L} 1$ and preclinical work demonstrated signaling through EGFR or $A L K$ upregulated PDL1 expression (27-29). However, results from clinical trials in this patient population have been disappointing.

In treatment naïve NSCLC patients with EGFR mutations, a phase II trial of single agent pembrolizumab as first line therapy was closed early due to futility (30). One of 11 patients experienced a partial response, but subsequent tissue analysis revealed non-mutated EGFR in the responder. For the patients with EGFR mutations, 7 of 10 experienced stable disease as their best response with a median PFS of 6.6 months. Notably, tumor PD-L1 expression was $\geq 50 \%$ in $70 \%$ of the patients with documented EGFR mutations, suggesting the PD-L1 biomarker is not predictive of benefit 
with pembrolizumab in patients with EGFR activating mutations. Of the seven patients who transitioned to TKI therapy post pembrolizumab, one experienced grade 3 transaminitis resulting in treatment discontinuation and another patient developed grade 5 pneumonitis (30). These concerning safety signals, including after the immunotherapy was completed, and lack of improved efficacy are also emerging from early trials of TKIs in combination with checkpoint inhibitors.

\section{First Line Checkpoint Inhibitors Plus TKI}

In patients with EGFR activating mutations without prior TKI exposure, several trials have reported early safety and efficacy data on EGFR directed TKIs in combination with checkpoint inhibitors. A multi-arm phase Ib trial suspended the cohort combining osimertinib and durvalumab due to 7 of the 11 treated patients developing interstitial lung disease (ILD), with three patients experiencing a grade $\geq 3$ ILD (31). Confirmed responses were observed in 70\% (95\%CI, 35-93) of the patients on combined therapy, a rate similar to first line osimertinib alone (32). In a phase Ib trial, erlotinib combined with atezolizumab demonstrated an ORR of $75 \%$ (95\%CI, 51-91) and there was a suggestion of a potential PFS benefit with median PFS 15 months (95\% CI, 8-not evaluable) (33). However, there were signs of increased toxicity with the erlotinib + atezolizumab combination, with grade 34 TRAEs of $46 \%$ compared to treatment emergent adverse event rates of $17-45 \%$ with erlotinib monotherapy (33-35). Gefitinib combined with durvalumab, generated no new safety signals compared to the TKI alone (36-38). As noted with the osimertinib data, the ORR for gefitinib plus durvalumab or erlotinib plus atezolizumab were similar to rates reported for TKI monotherapy (33-38). Pembrolizumab plus erlotinib or gefitinib resulted in discordant toxicities in a phase I/II trial (39). While the erlotinib combination was similar to erlotinib alone, gefitinib + pembrolizumab resulted in grade $3 / 4$ hepatic toxicity in 5 of the 7 treated patients. Even though it was tolerated, pembrolizumab + erlotinib resulted in a 41.7\% ORR, significantly lower than expected with erlotinib monotherapy. However, the PFS appeared to be improved with the combination (39).

For patients with metastatic $A L K+$ NSCLC, a similar theme of toxicity without clear improvement in efficacy has been observed. Cohort E of CheckMate370 evaluated crizotinib with nivolumab in treatment naïve patients and was stopped early after 5 of the first 13 patients developed grade $\geq 3$ hepatic toxicity, 2 of these 5 patients died (40). Efficacy appeared reduced with the combination as the ORR was only $38 \%$ compared to the expected ORR of $\sim 65 \%$ reported with crizotinib monotherapy in other trials (41). Hepatic and pancreatic toxicities lead to dose reductions of ceritinib in an ongoing phase I trial when combining the TKI with nivolumab (42). Alectinib plus atezolizumab in a phase $\mathrm{Ib}$ trial reported a grade $\geq 3$ TRAE rate of $52.4 \%$, a rate higher than expected for alectinib alone $(43,44)$. The addition of a checkpoint inhibitor to ceritinib or alectinib resulted in an ORR comparable to each TKI as first line monotherapy $(44,45)$.
Early trials reporting on a combination of TKI and checkpoint inhibitor suggest response rates equivalent to TKI alone and high potential for increased toxicity with these combinations in EGFR or $A L K+$ patients. Notably, retrospective data in patients with BRAF mutations suggest a benefit from checkpoint inhibitors in subsequent lines of therapy but no prospective data is available (46). As mature data becomes available for the ongoing trials, measures such as duration of response and time to next therapy will be critical. Whether the increased risk of these combinations is balanced by an efficacy benefit will help determine the direction of future trials, but due to the prolonged benefit seen with TKIs alone the data will likely be uninterpretable in the absence of randomization.

\section{Checkpoint Inhibitors Plus Chemotherapy Post TKI Progression}

Data has emerged on the combination of chemotherapy plus atezolizumab for advanced NSCLC patients with EGFR activating mutations or $A L K$ rearrangements previously treated with at least one approved TKI. IMpower150 compared bevacizumab + carboplatin + paclitaxel with or without atezolizumab and enrolled a small subset of EGFR or $A L K+$ patients $(n=108)$ $(19,20)$. EGFR or $A L K+$ patients experienced a median PFS of 9.7 months with ABCP compared to 6.1 months with BCP, HR 0.59 (95\%CI, 0.37-0.94). OS, while not statistically significant, appears to be trending toward an improvement with ACBP vs. BCP (not reached vs. 17.5 months, HR 0.54 (95\%CI 0.29-1.03). Subgroup analyses suggested the benefit in the EGFR/ALK+ patients may be predominately driven by patients with $E G F R$ exon 19 deletions and L858R point mutations in exon $21(n=59)$. In contrast to IMpower150, survival for the smaller EGFR/ALK+ subgroup in IMpower130 was not improved with atezolizumab + carboplatin + paclitaxel $(n=32)$ when compared to carboplatin + paclitaxel $(n=12)$, PFS HR 0.85 (95\%CI, 0.36-1.54), and OS HR 0.98 (95\%CI, 0.41-2.31) (21). Whether the benefit seen in IMpower150 is due to the addition of bevacizumab to chemotherapy plus atezolizumab or driven by patients with specific molecular alterations or whether some other imbalances existed between the arms to create a spurious result in this small subgroup within IMpower150 will need to be addressed in future trials.

\section{Selection of First Line Immunotherapy Options by Tumor Mutational Burden}

An emerging biomarker of interest for patients with metastatic NSCLC is tumor mutational burden (TMB). TMB is a measure of potential neoantigens that may be recognized by tumorreactive $\mathrm{T}$ cells and it is independent of $\mathrm{PD}-\mathrm{L} 1$ staining. An initial signal that TMB could predict responsiveness to immune checkpoint inhibitors was seen with nivolumab in CheckMate 026 (10). In a post-hoc analysis, patients with a high TMB by whole exome sequencing had a trend toward a better PFS with nivolumab compared to platinum-based chemotherapy, HR 0.62 (95\%CI, 0.38-1.00) (4).

A subsequent phase III trial, CheckMate 227, reported on 299 systemic therapy naïve patients with a TMB $\geq 10$ mutations/megabase by the Foundation Medicine targeted 
sequencing assay (11). Dual immune checkpoint blockade for patients with high TMB resulted in a median PFS of 7.2 vs. 5.5 months for platinum doublet chemotherapy, and at 1 year $43 \%$ of patients treated with nivolumab plus ipilimumab had not progressed vs. $13 \%$ of patients who received chemotherapy, PFS HR 0.58 (95\% CI, 0.41-0.81). Notably, PFS benefit was observed even in patients with high TMB and a PD-L1 level of $<1 \%$, HR 0.48 (95\% CI, 0.27-0.85). The PFS improvement did not translate into an OS benefit in the high TMB cohort as the recently updated data for nivolumab plus ipilimumab reported a median OS of 23.03 vs. 16.72 months for chemotherapy alone HR 0.77 (95\% CI 0.56-1.06) (47).

Similarly, subgroup analysis suggested high TMB may predict for improved outcomes with durvalumab + tremelimumab when compared to platinum-based doublets (12). The median OS was 16.5 vs. 10.5 months, 2 -year OS $39 \%$ vs. $18 \%$, HR 0.62 (95\% CI, 0.45-0.86). In both trials, patients stopped dual checkpoint blockade due to adverse events at a frequency similar to the rate reported for the discontinuation of pembrolizumab plus a platinum doublet $(17,24)$. Neither combination of PD-1/PDL1 axis blockade plus anti-CTLA-4 therapy are in the NCCN guidelines for NSCLC nor FDA approved but may find a place in therapy with mature trial data $(1,9)$.

\section{DISCUSSION}

Within the past few years, immunotherapy with checkpoint inhibitors has transformed first line therapy for patients with metastatic NSCLC. Prior to this, the most recent update to systemic therapy for newly diagnosed metastatic NSCLC without a driver mutation was the addition of pemetrexed in $2009(1,9)$.

Disrupting the binding of PD-1 to PD-L1 by blocking either partner may be considered equivalent when promoting a $\mathrm{T}$ cell response (48). However, the predominance of a PD-1 inhibitor in first line therapy for metastatic NSCLC suggests additional biologic determinants could also dictate a patient's response. Blocking PD-1 prevents inhibition through both PD-L1 and PD-L2, while blocking PD-L1 does not prevent PD-L2 mediated inhibition of T-cell function. Additionally, expression of PD-1, and PD-L1 varies across immune and nonimmune cell types and targeting one or the other may result in different subsets of cells responding to the tumor (49). The responding subsets of cells may better synergize with one class of chemotherapy than another based on the specific immune effects of each chemotherapy. Chemotherapy efficacy, while primarily driven by an apoptotic response to damage recognition at the level of a cell's DNA or the cell replication machinery, is also dependent on the immune system (50). Platinum agents, the backbone of chemotherapy for metastatic NSCLC, can increase antigen presentation by cancer cells, promote $\mathrm{T}$ cell trafficking into the tumor microenvironment, and decrease local immunosuppressive cells $(51,52)$. These significant alterations within the tumor microenvironment by platinum agents may not synergize as well with PD-L1 blockade because of the rapidly shifting tumor landscape. In contrast, PD-1 blockade targets a relatively static cell population in comparison, the $\mathrm{T}$ cell repertoire. Together these data suggest that better understanding the systemic immune impact of checkpoint inhibitors and chemotherapy are key to developing rational immunotherapy combinations for future trials.

While still in the formative years of incorporating checkpoint inhibitors into first line therapy for patients with metastatic NSCLC, most of the major trials use chemotherapy as a comparator. Therefore, it is not possible to say with good scientific rigor that a specific chemo-immunotherapy combination is more effective as none of these checkpoint inhibitors alone or in combination have been compared head to head. Several key questions remain about the clinical application of the different regimens and how to build upon the early successes (Figure 1).

Currently available clinical trial data does not clearly establish whether immunotherapy alone or immunotherapy and chemotherapy is the optimal management strategy for patients with PD-L1 $\geq 50 \%$ and no EGFR activating mutations or $A L K$ rearrangements. For such patients, comparing across studies, the chemo-immunotherapy combinations have a greater ORR compared to pembrolizumab monotherapy (Tables 1, 2). However, cross-trial comparisons may be complicated by the lack of uniform populations being explored, even when grouped by similar minimal levels of PD-L1 expression $(7,8)$. To date, PFS and OS with chemo-immunotherapy combinations do not yet appear different when compared to pembrolizumab monotherapy (Tables 1, 2). The absence of survival difference may be due to a shorter follow up in the chemo-immunotherapy trials or because of shorter duration of response with chemoimmunotherapy combinations when compared to responses to pembrolizumab alone. Continued translational research is necessary to define patient subsets and biomarkers that may better inform treatment choices for those patients with PD-L1 $\geq 50 \%$.

Of the biomarkers currently in clinical use, a retrospective single arm study of patients with PD-L1 $\geq 50 \%$ treated with pembrolizumab monotherapy suggested raising the PD-L1 cutpoint to $\geq 90 \%$ on tumor cells may enrich for patients who benefit from pembrolizumab monotherapy (53). Patients with $\geq 90 \%$ PD-L1 experienced an ORR of 55\% (33 of 60) vs. $25.2 \%$ (22 of 87 ) in patients with $50-89 \%$ staining. This cutoff also resulted in improved PFS and OS with a median OS of 33.6 months $(95 \% \mathrm{CI}$, not reached-not reached) for patients with PD-L1 $\geq 90 \%$ compared to 15.2 months (95\%CI, 11.625.6) in patients with PD-L1 of $50-89 \%$ (53). The power of multiple immune biomarkers was illustrated in a retrospective study across multiple tumor types from 4 KEYNOTE trials (54). While these patients were treated with pembrolizumab in subsequent lines of therapy, a combination of TMB and T cell gene expression profile in the tumor microenvironment enriched for those who responded to immunotherapy and, of equal importance, robustly identified those who did not respond. While encouraging and hypothesis generating, the clear limitation of these retrospective studies is the lack of a comparator reflective of clinical options. Even more challenging, robust predictors for patients who benefit from chemo-immunotherapy have not been identified. While PD-L1 staining appears to have a modest 


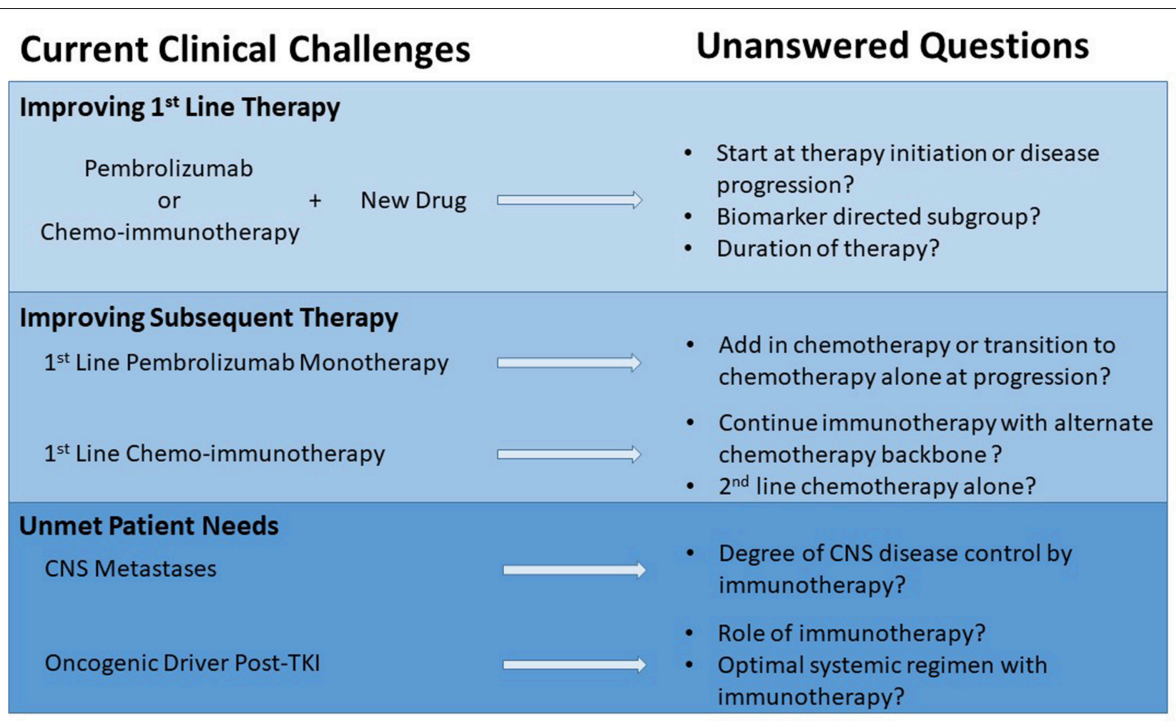

FIGURE 1 | Opportunities in metastatic NSCLC to maximize impact of checkpoint inhibitors.

association with outcome, in most studies patients at all PDL1 levels, including PD-L1 negative patients, appear to benefit. Clearly, continued collection, and study of biospecimens from all patients starting immunotherapy alone or in combination is a priority to improve patient selection for therapies and inform trials testing drug combinations with immunotherapy.

In the absence of clear data, patient performance status and clinical scenario often drive the selection of pembrolizumab monotherapy or combined chemo-immunotherapy for those with $\mathrm{PD}-\mathrm{L} 1 \geq 50 \%$. While pembrolizumab monotherapy is much better tolerated compared to available chemo-immunotherapy combinations, it is worth noting that historically $1 / 3$ to $1 / 2$ of patients do not receive second line therapy (55). For the first time in the immune checkpoint inhibitor era, available initial therapy options and subsequent therapy sequencing will be tested in a randomized phase III trial, the INSIGNA study. This trial is planned to enroll 800 patients with any histology metastatic NSCLC with PD-L1 $\geq 1 \%$ (stratified by whether levels are $\geq 50 \%$ or less) and will be randomized to one of three arms. One arm will treat patients with pembrolizumab plus histology directed chemotherapy (56). The two other arms will start patients on pembrolizumab monotherapy but at time of progression one will transition to chemotherapy alone and the other will transition to chemotherapy plus continued pembrolizumab. This trial will be the first head to head comparison between pembrolizumab monotherapy and chemo-immunotherapy and may provide clearer guidance on how to manage patients after progression on pembrolizumab monotherapy, an urgent clinical need. What is not readily addressed by the INSIGNA trial is how to manage patients postprogression on chemo-immunotherapy. Standard of care may include docetaxel \pm ramucirumab or other chemotherapies (e.g., gemcitabine). However, these standard treatments generally have short survival benefit. An important future question is whether the checkpoint inhibitor should be continued in this setting but with an alternative chemotherapy backbone.

Future approaches to improve responses and outcomes for patients who start immunotherapy with or without chemotherapy are pembrolizumab combinations with a novel drug as initial treatment and several trials in this paradigm are ongoing in patients with PD-L1 $\geq 50 \%$ (Table 4). Most of these trials are in phase I or II of testing and not all are randomized or use pembrolizumab alone as a comparator arm so definitive answers are likely years away. Similar trials are underway for pembrolizumab + chemotherapy (Table 4).

For patients with prolonged PFS on first line pembrolizumab or chemo-immunotherapy, duration of treatment has been dictated by the development of toxicity or disease progression. While early data in patients with metastatic melanoma suggest highly selected patients can stop checkpoint inhibition and maintain response, less is known about patients with metastatic NSCLC. In a small randomized study, patients with NSCLC on second line nivolumab for at least 1 year were randomized to continue nivolumab $(n=76)$ or stop therapy $(n=87)$ in CheckMate-153. PFS favored continuous therapy (HR 0.42, 95\% CI 0.25-0.71), but OS was not significantly different (57). While outcome data favored continuous therapy, over half of patients on observation alone continued to experience a response of stable disease or better with a median follow up of 14.9 months. Conclusions are difficult to draw and apply to first line therapy, but it highlights the recurring theme that a cohort of patients experience prolonged, durable benefit from checkpoint inhibitors and efficacy is not completely dependent on scheduled dosing. While a challenging prospect based on the range of patient response and need for continued therapy, future trials addressing maintenance dosing after first line immunotherapy \pm chemotherapy are important for patient quality of life and reducing long-term toxicities. 
TABLE 4 | Select ongoing first line trials for patients with metastatic NSCLC and PD-L1 $\geq 50 \%$ on tumor cells.

\begin{tabular}{|c|c|c|c|c|}
\hline Regimen & Study design & NCT number & Primary outcome & Estimated completion date \\
\hline $\begin{array}{l}\text { Pembrolizumab + Decitabine + } \\
\text { Tetrahydrouridine }\end{array}$ & Single arm phase I/II & NCT03233724 & MTD and ORR & December 31, 2020 \\
\hline Pembrolizumab + Itacitinib & Single arm phase II & NCT03425006 & ORR at 12 weeks and toxicity & June 2021 \\
\hline Pembrolizumab + AGEN1884 & Single arm phase ॥ & NCT03411473 & DLT incidence & May 2021 \\
\hline $\begin{array}{l}\text { Pembrolizumab + } \\
\text { GRN1201/sargramostim }\end{array}$ & Single arm phase ॥ & NCT03417882 & ORR & March 2021 \\
\hline $\begin{array}{l}\text { Pembrolizumab + AM0010 vs. } \\
\text { Pembrolizumab (Cypress 1) }\end{array}$ & Randomized phase II & NCT03382899 & ORR & December 2021 \\
\hline $\begin{array}{l}\text { Pembrolizumab + Ipilimumab vs. } \\
\text { Pembrolizumab + Placebo } \\
\text { (KEYNOTE-598) }\end{array}$ & Randomized phase III & NCT03302234 & PFS and OS & February 22, 2024 \\
\hline $\begin{array}{l}\text { Pembrolizumab + } 10102 \text { vs. } \\
\text { Pembrolizumab and Pembrolizumab + } \\
\text { Carboplatin + Pemetrexed + } 10102 \text { vs. } \\
\text { Pembrolizumab + Carboplatin + } \\
\text { Pemetrexed }\end{array}$ & Randomized phase I/II & NCT03562871 & DLT incidence, ORR & February 2022 \\
\hline $\begin{array}{l}\text { Pembrolizumab + Carboplatin + } \\
\text { Pemetrexed + NEO-PV-01/Adjuvant }\end{array}$ & Phase I & NCT03380871 & DLT incidence & February 2021 \\
\hline $\begin{array}{l}\text { Pembrolizumab + Platinum + Pemetrexed } \\
+ \text { Canakinumab vs. Pembrolizumab + } \\
\text { Platinum + Pemetrexed (CANOPY-1) }\end{array}$ & Phase III & NCT03631199 & DLT incidence, PFS, and OS & October 21, 2022 \\
\hline
\end{tabular}

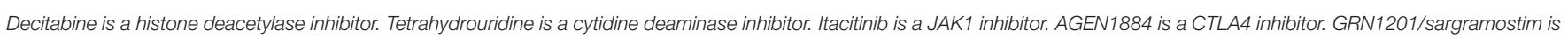

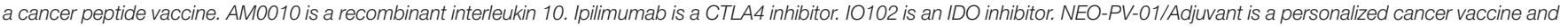

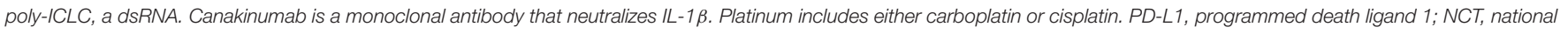
clinical trials; ORR, objective response rate; PFS, progression free survival; OS, overall survival; DLT, dose limiting toxicity; MTD, maximum tolerated dose.

Several groups of patients with metastatic NSCLC have not yet benefitted from immunotherapy either due to poor responses or lack of inclusion in trials. Early data in never smoking patients have suggested immunotherapy alone does not significantly improve PFS or OS over chemotherapy $(5-7,10)$. Thus, regardless of PD-L1 staining levels, caution may need to be utilized in this patient population before administering immune checkpoint inhibition without chemotherapy as first line treatment. In these patients, proper molecular testing should be done to exclude targetable oncogenic drivers, for which approved TKIs would be the preferred initial therapy.

The role of chemo-immunotherapy combinations after progression on TKIs is not clear since the data from both IMpower130 and IMpower150 was based on small subset analyses in patients with EGFR activating mutations/ALK rearrangements. This lack of clarity is reflected in the differing approvals by governing bodies, with the FDA not approving ABCP for patients with EGFR activating mutations/ALK rearrangements, and other areas of the world (e.g., the European Medicines Agency) approving ABCP for patients with these genetic subsets of NSCLC. IMpower130, with a subgroup of 44 patients, suggests chemotherapy plus immunotherapy does not benefit $E G F R / A L K+$ patients which is in line with nearly all prospective and retrospective studies trying to find a role for monotherapy with immune checkpoint inhibitors in this patient cohort (21). IMpower150 included 108 patients with $E G F R / A L K+$ disease and reported a PFS improvement with the addition of bevacizumab to the IMpower130 regimen, especially in the EGFR+ patients with an exon 19 deletion or
L858R point mutation $(18,19)$. Bevacizumab has been shown to reduce Treg accumulation in tumors and attenuate Treg expansion in the peripheral blood (58). One interpretation is that multiple alterations of local and systemic immunity are necessary for checkpoint inhibition to benefit patients with a targetable oncogenic driver. The discrepancies between the IMpower studies may be clarified with a phase II trial which will randomize never smokers or those with an EGFR, $A L K$, or ROS1 driver after at least 1 TKI to carboplatin + pemetrexed + bevacizumab with or without atezolizumab (Table 5). In part, the potential for specific molecular alterations being more likely to respond to immune checkpoint inhibition plus chemotherapy will be addressed in KEYNOTE-789 (Table 5). This phase III trial will randomize patients with an EGFR exon 19 deletion or EGFR L858R point mutation in exon 21 to pemetrexed and a platinum \pm pembrolizumab after progression on an EGFR directed TKI. CheckMate722 will test nivolumab $+\mathrm{a}$ platinum doublet chemotherapy and nivolumab +ipilimumab against standard chemotherapy for patients with EGFR activating mutations who have progressed after at least one TKI. While data for KEYNOTE-789, CheckMate722, and other planned trials will likely inform clinical practice, for now it is unclear where chemotherapy plus immunotherapy fits, if at all, into the therapy schema of patients with targetable oncogenic drivers (Table 5).

Finally, an estimated $26 \%$ of newly diagnosed stage IV NSCLC patients present with brain metastases and very few patients with untreated CNS disease were enrolled on the trials that have redefined first line therapy for metastatic NSCLC (59). In patients with metastatic NSCLC receiving 
TABLE 5 | Select chemo-immunotherapy trials for chemotherapy Naïve NSCLC patients with EGFR activating mutations or ALK rearrangements.

\begin{tabular}{|c|c|c|c|c|c|}
\hline Regimen & Patient population & Study design & NCT number & Primary outcome & $\begin{array}{l}\text { Estimated } \\
\text { completion date }\end{array}$ \\
\hline $\begin{array}{l}\text { Atezolizumab + Carboplatin + } \\
\text { Pemetrexed + Bevacizumab vs. } \\
\text { Carboplatin + Pemetrexed + } \\
\text { Bevacizumab }\end{array}$ & $\begin{array}{l}\text { Non-smokers (<100 cigarettes } \\
\text { in a life time), EGFR activating } \\
\text { mutation, or ALK or ROS1 } \\
\text { rearrangement positive }\end{array}$ & Randomized phase II & NCT03786692 & PFS & January 2024 \\
\hline $\begin{array}{l}\text { Nivolumab + Carboplatin + Pemetrexed } \\
\text { vs. Nivolumab + Ipilimumab }\end{array}$ & $\begin{array}{l}\text { EGFR activating mutation or } A L K \\
\text { rearrangement positive }\end{array}$ & Randomized phase II & NCT03256136 & ORR & October 31, 2024 \\
\hline $\begin{array}{l}\text { Pembrolizumab + Platinum + Pemetrexed } \\
\text { vs. Platinum + Pemetrexed } \\
\text { (KEYNOTE-789) }\end{array}$ & $\begin{array}{l}\text { EGFR activating mutation } \\
\text { positive }\end{array}$ & Randomized phase III & NCT03515837 & PFS and OS & June 26, 2023 \\
\hline $\begin{array}{l}\text { Nivolumab + Platinum + Pemetrexed vs. } \\
\text { Nivolumab + Ipilimumab vs. Platinum + } \\
\text { Pemetrexed (CheckMate722) }\end{array}$ & $\begin{array}{l}\text { EGFR activating mutation } \\
\text { positive }\end{array}$ & Randomized phase III & NCT02864251 & PFS & December 31, 2023 \\
\hline
\end{tabular}

Platinum includes either carboplatin or cisplatin. PD-L1, programmed death ligand 1; NCT, national clinical trials; ORR, objective response rate; PFS, progression free survival; OS, overall survival.

pembrolizumab as a subsequent line of therapy, a small phase II study enrolled patients with limited, asymptomatic brain metastases who either were untreated or progressed after local therapy (60). One third of patients with PD-L1 positive tumors and CNS disease experienced a response while no responses were observed in patients with PD-L1 negative or unevaluable PD-L1 status. Additionally, early trial data from metastatic melanoma has suggested that CNS responses can be achieved with immune checkpoint inhibitors alone in first line therapy $(60,61)$. With these initial safety and efficacy signals, future first line immunotherapy trials should include this cohort of lung cancer patients to better understand the scope of CNS disease control by PD-1 vs. PD-L1 checkpoint inhibitors given the potential different cell distribution of the respective drug targets and their location relative to the blood brain barrier. Additionally, the role of PD-L1 expression in predicting response to these drugs in untreated CNS disease needs to be better evaluated.

\section{CONCLUSION}

In the span of only a few years, immunotherapy has transformed the treatment of patients with metastatic NSCLC. In cohorts with

\section{REFERENCES}

1. National Comprehensive Cancer Network. Non-Small Cell Lung Cancer (Version 3.2019). Available online at: https://www.nccn.org/professionals/ physician_gls/pdf/nscl.pdf (Accessed February 6, 2019).

2. Langer CJ. Emerging immunotherapies in the treatment of non-small cell lung cancer (NSCLC): the role of immune checkpoint inhibitors. Am J Clin Oncol. (2015) 38:422-30. doi: 10.1097/COC.0000000000000059

3. Zou W, Wolchok JD, Chen L. PD-L1 (B7-H1) and PD-1 pathway blockade for cancer therapy: Mechanisms, response biomarkers, and combinations. Sci Transl Med. (2016) 8:328rv4. doi: 10.1126/scitranslmed.aad7118

4. Hodi FS. Cytotoxic T-lymphocyte-associated antigen-4. Clin Cancer Res. (2007) 13:5238-42. doi: 10.1158/1078-0432.CCR07-0813 high PD-L1 and no targetable oncogene, survival is approaching years rather than months with the previous chemotherapy standard of care. Remarkably, the pairing of chemotherapy and checkpoint inhibition is benefitting patients without high PDL1 to a similar degree. While the wait for success in the field of cancer immunotherapy and for patients with metastatic NSCLC has been long, these accomplishments should be a building block for developing future therapies and clinical trials. Multiple clinical challenges remain to maximize patient benefit from currently available therapy and continued translational research is necessary to develop rational frameworks in which to test the next generation of immunotherapy.

\section{AUTHOR CONTRIBUTIONS}

JP and ES identified relevant clinical trials and wrote the initial draft of the manuscript. JP, ES, DC and RD contributed to manuscript revision, read, and approved the submitted version.

\section{FUNDING}

The work of DC and RD was partially supported by the University of Colorado Lung Cancer SPORE (P50CA058187). 
(chemo) as first-line therapy for advanced/metastatic NSCLC with a PD-L1 tumor proportion score (TPS) $\geq 1 \%$ : Open-label, phase 3 KEYNOTE-042 study. J Clin Oncol. (2018) 36(18_suppl.):LBA4. doi: 10.1200/JCO.2018.36.18_suppl.LBA4

9. United States Food and Drug Administration. Available online at: www.FDA. gov. (Accessed January 29, (2019).

10. Carbone DP, Reck M, Paz-Ares L, Creelan B, Horn L, Steins M, et al. First-line nivolumab in stage IV or recurrent non-small-cell lung cancer. $N$ Engl J Med. (2017) 376:2415-26. doi: 10.1056/NEJMoa1613493

11. Hellmann MD, Ciuleanu TE, Pluzanski A, Lee JS, Otterson GA, AudigierValette C, et al. Nivolumab plus Ipilimumab in lung cancer with a high tumor mutational burden. N Engl J Med. (2018) 378:2093-104. doi: 10.1056/NEJMoa1801946

12. Rizvi NCB, Reinmuth N, Lee KH, Ahn MJ, Luft A, van den Heuvel $\mathrm{M}$, et al. Durvalumab with or without Tremelimumab vs. Platinum-based chemotherapy as first-line treatment for metastatic non-small cell lung cancer: MYSTIC. In: European Society of Medical Oncology Annual Meeting. Munich (2018)

13. Hellmann MD, Rizvi NA, Goldman JW, Gettinger SN, Borghaei H, Brahmer JR, et al. Nivolumab plus ipilimumab as first-line treatment for advanced non-small-cell lung cancer (CheckMate 012): results of an open-label, phase 1, multicohort study. Lancet Oncol. (2017) 18:31-41. doi: 10.1016/S1470-2045(16)30624-6

14. Goldman JW, Antonia SJ, Gettinger SN, Borghaei H, Brahmer JR, Ready NE, et al. Nivolumab (N) plus ipilimumab (I) as first-line (1L) treatment for advanced (adv) NSCLC: 2-yr OS and long-term outcomes from CheckMate 012. J Clin Oncol. (2017). 35(15 suppl.):9093. doi: 10.1200/JCO.2017.35.15_suppl.9093

15. Verschraegen CF, Chen F, Spigel DR, Iannotti N, McClay EF, Redfern CH, et al. Avelumab (MSB0010718C; anti-PD-L1) as a first-line treatment for patients with advanced NSCLC from the JAVELIN solid tumor phase $1 \mathrm{~b}$ trial: safety, clinical activity, and PD-L1 expression. J Clin Oncol. (2016) 34(15_suppl.):9036. doi: 10.1200/JCO.2016.34.15

16. Gandhi L, Rodgríguez-Abreu D, Gadgeel S, Esteban E, Felip E, De Angelis F, et al. Abstract CT075: KEYNOTE-189: Randomized, doubleblind, phase 3 study of pembrolizumab (pembro) or placebo plus pemetrexed (pem) and platinum as first-line therapy for metastatic NSCLC. Cancer Res. (2018) 78(13 Suppl.): CT075. doi: 10.1158/1538-7445.AM2018CT075

17. Gandhi L, Rodríguez-Abreu D, Gadgeel S, Esteban E, Felip E, De Angelis F, et al. Pembrolizumab plus chemotherapy in metastatic non-small-cell lung cancer. N Engl J Med. (2018) 378:2078-92. doi: 10.1056/NEJMoa1 801005

18. Socinski MA, Jotte RM, Cappuzzo F, Orlandi F, Stroyakovskiy D, Nogami $\mathrm{N}$, et al. Atezolizumab for first-line treatment of metastatic nonsquamous NSCLC. N Engl J Med. (2018) 378:2288-301. doi: 10.1056/NEJMoa1716948

19. Kowanetz M, Socinski MA, Zou W, McCleland M, Yang N, Chavez AL, et al. Abstract CT076: IMpower150: efficacy of atezolizumab (atezo) plus bevacizumab (bev) and chemotherapy (chemo) in 1L metastatic nonsquamous NSCLC (mNSCLC) across key subgroups. Cancer Res. (2018) 78(13 Suppl.):CT076. doi: 10.1158/1538-7445.AM2018-CT076

20. Socinski MA, Jotte RM, Cappuzzo F, Orlandi FJ, Stroyakovskiy D, Nogami $\mathrm{N}$, et al. Overall survival (OS) analysis of IMpower150, a randomized $\mathrm{Ph} 3$ study of atezolizumab (atezo) + chemotherapy (chemo) \pm bevacizumab (bev) vs. chemo + bev in 1L nonsquamous (NSQ) NSCLC). J Clin Oncol. (2018) 36(15_suppl.): 9002. doi: 10.1200/JCO.2018.36.15_suppl.9002

21. Cappuzzo F, McCleod M, Hussein M, Morabito A, Rittmeyer A, Conter $\mathrm{HJ}$, et al. IMpower130: efficacy and safety from a randomisedphase 3 study of carboplatin and nab-paclitaxel with or without atezolizumab in 1L advanced non-squamous NSCLC. Ann Oncol. (2018) 29:mdy424.065. doi: 10.1093/annonc/mdy424.065

22. Papadimitrakopoulou VA, Cobo M, Bordoni R, Longeras PD, Szalai Z, Ursol G, et al. OA05.07 IMpower132: PFS and safety results with 1L Atezolizumab + Carboplatin/Cisplatin + Pemetrexed in Stage IV non-squamous NSCLC. J Thorac Oncol. (2008) 13:S332-3. doi: 10.1016/j.jtho.2018.08.262

23. Paz-Ares LG, Luft A, Tafreshi A, Gumus M, Mazieres J, Hermes B, et al. Phase 3 study of carboplatin-paclitaxel/nab-paclitaxel (Chemo) with or without pembrolizumab (Pembro) for patients (Pts) with metastatic squamous (Sq) non-small cell lung cancer (NSCLC). J Clin Oncol. (2018) 36(15_suppl.):105. doi: 10.1200/JCO.2018.36.15_suppl.105

24. Paz-Ares L, Luft A, Vicente D, Tafreshi A, Gümüş M, Mazières J, et al Pembrolizumab plus chemotherapy for squamous non-small-cell lung cancer. N Engl J Med. (2018) 379:2040-51. doi: 10.1056/NEJMoa1810865

25. Jotte RM, Cappuzzo F, Vynnychenko I, Stroyakovskiy D, Abreu DR, Hussein MA, et al. IMpower131: Primary PFS and safety analysis of a randomized phase III study of atezolizumab + carboplatin + paclitaxel or nab-paclitaxel vs. carboplatin + nab-paclitaxel as $1 \mathrm{~L}$ therapy in advanced squamous NSCLC. J Clin Oncol. (2018) 36(18_suppl.):LBA9000. doi: 10.1200/JCO.2018.36.18_suppl.LBA9000

26. Avelumab in First-line Non-Small Cell Lung Cancer (JAVELIN Lung 100). Available online at: https://ClinicalTrials.gov/show/NCT02576574.

27. Akbay EA, Koyama S, Carretero J, Altabef A, Tchaicha JH, Christensen $\mathrm{CL}$, et al. Activation of the PD-1 pathway contributes to immune escape in EGFR-driven lung tumors. Cancer Discov. (2013) 3:1355-63. doi: 10.1158/2159-8290.CD-13-0310

28. Ota K, Azuma K, Kawahara A, Hattori S, Iwama E, Tanizaki J, et al. Induction of PD-L1 expression by the EML4-ALK oncoprotein and downstream signaling pathways in non-small cell lung cancer. Clin Cancer Res. (2015) 21:4014-21. doi: 10.1158/1078-0432.CCR-15-0016

29. D’Incecco A, Andreozzi M, Ludovini V, Rossi E, Capodanno A, Landi L, et al. PD-1 and PD-L1 expression in molecularly selected non-small-cell lung cancer patients. Br J Cancer. (2014) 112:95. doi: 10.1038/bjc.2014.555

30. Lisberg A, Cummings A, Goldman JW, Bornazyan K, Reese N, Wang T, et al. A phase II study of pembrolizumab in EGFR-mutant, PD-L1+, Tyrosine Kinase inhibitor naive patients with advanced NSCLC. J Thorac Oncol. (2018) 13:1138-45. doi: 10.1016/j.jtho.2018.03.035

31. Ahn MJ, Yu H, Saka H, Ramalingam S, Goto K, Kim S-W, et al. $136 \mathrm{O}$ : Osimertinib combined with durvalumab in EGFR-mutant non-small cell lung cancer: results from the TATTON phase Ib trial. J Thorac Oncol. (2016) 11(4 Suppl.):S115. doi: 10.1016/S1556-0864(16)30246-5

32. Soria J-C, Ohe Y, Vansteenkiste J, Reungwetwattana T, Chewaskulyong B, Lee $\mathrm{KH}$, et al. Osimertinib in untreated EGFR-mutated advanced non-small-cell lung cancer. N Engl J Med. (2018) 378:113-25. doi: 10.1056/NEJMoa1713137

33. Rudin CM, Cervantes A, Dowlati A, Besse B, Ma A, Costa D, et al. MA15.02: long-term safety and clinical activity results from a phase ib study of atezolizumab plus erlotinib in advanced NSCLC. In: Presented at the IASLC World Conference on Lung Cancer. Toronto, ON (2018).

34. Rosell R, Carcereny E, Gervais R, Vergnenegre A, Massuti B, Felip E, et al. Erlotinib versus standard chemotherapy as first-line treatment for European patients with advanced EGFR mutation-positive non-small-cell lung cancer (EURTAC): a multicentre, open-label, randomised phase 3 trial. Lancet Oncol. (2012) 13:239-46. doi: 10.1016/S1470-2045(11)70393-X

35. Zhou C, Wu YL, Chen G, Feng J, Liu XQ, Wang C, et al. Erlotinib versus chemotherapy as first-line treatment for patients with advanced EGFR mutation-positive non-small-cell lung cancer (OPTIMAL, CTONG-0802): a multicentre, open-label, randomised, phase 3 study. Lancet Oncol. (2011) 12:735-42. doi: 10.1016/S1470-2045(11)70184-X

36. Gibbons DL, Chow LQ, Kim D-W, Kim S-W, Yeh T, Song X, et al 570 efficacy, safety and tolerability of MEDI4736 (durvalumab [D]), a human IgG1 anti-programmed cell death-ligand-1 (PD-L1) antibody, combined with gefitinib (G): A phase I expansion in TKI-naive patients (pts) with EGFR mutant NSCLC. J Thorac Oncol. (2016) 11:S79. doi: 10.1016/S1556-0864(16)30171-X

37. Maemondo $M$, Inoue A, Kobayashi $K$, Sugawara S, Oizumi S, Isobe $H$, et al. Gefitinib or chemotherapy for non-small-cell lung cancer with mutated EGFR. N Engl J Med. (2010) 362:2380-8. doi: 10.1056/NEJMoa0909530

38. Mitsudomi T, Morita S, Yatabe Y, Negoro S, Okamoto I, Tsurutani J, et al. Gefitinib versus cisplatin plus docetaxel in patients with non-small-cell lung cancer harbouring mutations of the epidermal growth factor receptor (WJTOG3405): an open label, randomised phase 3 trial. Lancet Oncol. (2010) 11:121-8. doi: 10.1016/S1470-2045(09)70364-X

39. Yang JC-H, Gadgeel SM, Sequist LV, Wu CL, Papadimitrakopoulou VA, Su WC, et al. Brief report: pembrolizumab in combination with erlotinib or gefitinib as first-line therapy for advanced non-small-cell lung 
cancer with sensitizing EGFR mutation. J Thorac Oncol. (2018) 4:553-9. doi: $10.1016 /$ j.jtho.2018.11.028

40. Spigel DR, Reynolds C, Waterhouse D, Garon EB, Chandler J, Babu S, et al. Phase 1/2 study of the safety and tolerability of Nivolumab plus crizotinib for the first-line treatment of anaplastic lymphoma kinase translocation positive advanced non-small cell lung cancer (CheckMate 370). J Thorac Oncol. (2018). 13:682-8. doi: 10.1016/j.jtho.2018.02.022

41. Shaw AT, Kim DW, Nakagawa K, Seto T, Crinó L, Ahn MJ, et al. Crizotinib versus chemotherapy in advanced ALK-positive lung cancer. $N$ Engl J Med. (2013) 368:2385-94. doi: 10.1056/NEJMoa1214886

42. Felip E, De Braud FG, Maur M, Loong HHF, Shaw AT, Vansteenkiste JF, et al. Ceritinib plus nivolumab (NIVO) in patients (pts) with anaplastic lymphoma kinase positive (ALK+) advanced non-small cell lung cancer (NSCLC). J Clin Oncol. (2017) 35(15_suppl.): 2502. doi: 10.1200/JCO.2017.35.15_suppl.2502

43. Kim D-W, Gadgeel SM, Gettinger CN, Riely GJ, Oxnard GR, Mekhail T, et al. Safety and clinical activity results from a phase Ib study of alectinib plus atezolizumab in ALK+ advanced NSCLC (aNSCLC). J Clin Oncol. (2018) 36(15_suppl.):9009. doi: 10.1200/JCO.2018.36.15_suppl.9009

44. Peters S, Camidge DR, Shaw AT, Gadgeel S, Ahn JS, Kim DW, et al. Alectinib versus Crizotinib in untreated ALK-positive non-small-cell lung cancer. $N$ Engl J Med. (2017) 377:829-38. doi: 10.1056/NEJMoa1704795

45. Soria JC, Tan DSW, Chiari R, Wu YL, Paz-Ares L, Wolf J, et al. First-line ceritinib versus platinum-based chemotherapy in advanced ALK-rearranged non-small-cell lung cancer (ASCEND-4): a randomised, open-label, phase 3 study. Lancet. (2017) 389:917-29. doi: 10.1016/S0140-6736(17)30123-X

46. Dudnik E, Peled N, Nechushtan H, Wollner M, Onn A, Agbarya A, et al. BRAF mutant lung cancer: programmed death ligand 1 expression, tumor mutational burden, microsatellite instability status, and response to immune check-point inhibitors. J Thorac Oncol. (2018) 13:1128-37. doi: 10.1016/j.jtho.2018.04.024

47. Squibb B-M. Bristol-Myers Squibb Reports Fourth Quarter and Full Year Financial Results. Available online at: https://news.bms.com/press-release/ corporatefinancial-news/bristol-myers-squibb-provides-update-ongoingregulatory-review (accessed February 9, 2019).

48. Ostrand-Rosenberg S, Horn LA, Haile ST. The programmed death-1 immunesuppressive pathway: barrier to antitumor immunity. J Immunol. (2014) 193:3835-41. doi: 10.4049/jimmunol.1401572

49. Keir ME, Butte MJ, Freeman GJ, Sharpe AH. PD-1 and its ligands in tolerance and immunity. Annu Rev Immunol. (2008) 26:677-704. doi: 10.1146/annurev.immunol.26.021607.090331

50. Zitvogel L, Galluzzi L, Smyth MJ, Kroemer G. Mechanism of action of conventional and targeted anticancer therapies: reinstating immunosurveillance. Immunity. (2013) 39:74-88. doi: 10.1016/j.immuni. 2013.06.014

51. de Biasi AR, Villena-Vargas J, Adusumilli PS. Cisplatin-induced antitumor immunomodulation: a review of preclinical and clinical evidence. Clin Cancer Res. (2014) 20:5384-91. doi: 10.1158/1078-0432.CCR-14-1298

52. Galluzzi L, Buqué A, Kepp O, Zitvogel L, Kroemer G. Immunological effects of conventional chemotherapy and targeted anticancer agents. Cancer Cell. (2015) 28:690-714. doi: 10.1016/j.ccell.2015.10.012
53. Jimenez Alguilar E, Gainor J, Kravets S, Khosrowjerdi S, Lydon C, Adeni A, et al. MA04.05 outcomes in NSCLC patients treated with first-line pembrolizumab and a PD-L1 TPS of $50-74 \%$ vs. $75-100 \%$ or $50-89 \%$ vs. 90-100\%.J Thorac Oncol. (2018) 13:S367-8. doi: 10.1016/j.jtho.2018.08.343

54. Cristescu R, Mogg R, Ayers M, Albright A, Murphy E, Yearley J, et al. Pan-tumor genomic biomarkers for PD-1 checkpoint blockade-based immunotherapy. Science. (2018) 362: eaar3593. doi: 10.1126/science.aar3593

55. Davies J, Patel M, Gridelli C, de Marinis F, Waterkamp D, McCusker ME. Real-world treatment patterns for patients receiving second-line and third-line treatment for advanced non-small cell lung cancer: a systematic review of recently published studies. PLoS ONE. (2017) 12:e0175679. doi: 10.1371/journal.pone.0175679

56. Firstline Pembrolizumab Alone or in Combination With Pemetrexed and Carboplatin in Induction/Maintenance or Postprogression in Treating Patients With Stage IV Non-squamous Non-small Cell Lung Cancer. Available online at: https://ClinicalTrials.gov/show/NCT03793179.

57. Spigel DR, McLeod M, Hussein MA, Waterhouse DM, Horn L, Einhorn L, et al. $1297 \mathrm{O}$ Randomized results of fixed-duration (1-yr) vs. continuous nivolumab in patients (pts) with advanced non-small cell lung cancer (NSCLC). Ann Oncol. (2017) 28(suppl_5):v460-96. doi: 10.1093/annonc/mdx380

58. Terme M, Pernot S, Marcheteau E, Sandoval F, Benhamouda N, Colussi O, et al. VEGFA-VEGFR pathway blockade inhibits tumor-induced regulatory T-cell proliferation in colorectal cancer. Cancer Res. (2013) 73:539-49. doi: 10.1158/0008-5472.CAN-12-2325

59. Waqar SN, Samson PP, Robinson CG, Bradley J, Devarakonda S, Du L, et al. Non-small-cell lung cancer with brain metastasis at presentation. Clin Lung Cancer. (2018) 19:e373-9. doi: 10.1016/j.cllc.2018.01.007

60. Goldberg SB, Gettinger SN, Mahajan A, Herbst RS, Chiang AC, Lilenbaum R, et al. Durability of brain metastasis response and overall survival in patients with non-small cell lung cancer (NSCLC) treated with pembrolizumab. J Clin Oncol. (2018) 36(15_suppl):2009. doi: 10.1200/JCO.2018.36.15 _suppl.2009

61. Goldberg SB, Gettinger SN, Mahajan A, Chiang AC, Herbst RS, Sznol $\mathrm{M}$, et al. Pembrolizumab for patients with melanoma or non-small-cell lung cancer and untreated brain metastases: early analysis of a nonrandomised, open-label, phase 2 trial. Lancet Oncol. (2016) 17:976-83. doi: 10.1016/S1470-2045(16)30053-5

Conflict of Interest Statement: The authors declare that the research was conducted in the absence of any commercial or financial relationships that could be construed as a potential conflict of interest.

Copyright $\odot 2019$ Pacheco, Camidge, Doebele and Schenk. This is an open-access article distributed under the terms of the Creative Commons Attribution License (CC $B Y)$. The use, distribution or reproduction in other forums is permitted, provided the original author(s) and the copyright owner(s) are credited and that the original publication in this journal is cited, in accordance with accepted academic practice. No use, distribution or reproduction is permitted which does not comply with these terms. 